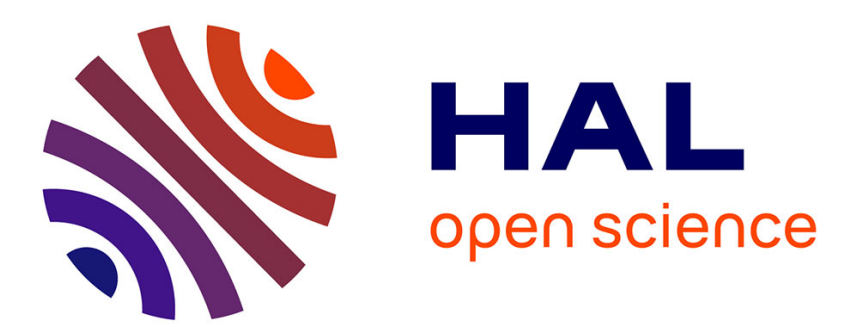

\title{
A Sustainable Reconfigurable Manufacturing System Designing With Focus On Environmental Hazardous Wastes
}

\author{
Amirhossein Khezri, Hichem Haddou Benderbal, Lyes Benyoucef
}

\section{- To cite this version:}

Amirhossein Khezri, Hichem Haddou Benderbal, Lyes Benyoucef. A Sustainable Reconfigurable Manufacturing System Designing With Focus On Environmental Hazardous Wastes. IEEE 23rd International Conference on Emerging Technologies and Factory Automation ( ETFA2019), Sep 2019, Zaragoza, Spain. pp.317-324, 10.1109/ETFA.2019.8869380 . hal-02136973

\section{HAL Id: hal-02136973 \\ https://hal-amu.archives-ouvertes.fr/hal-02136973}

Submitted on 22 May 2020

HAL is a multi-disciplinary open access archive for the deposit and dissemination of scientific research documents, whether they are published or not. The documents may come from teaching and research institutions in France or abroad, or from public or private research centers.
L'archive ouverte pluridisciplinaire HAL, est destinée au dépôt et à la diffusion de documents scientifiques de niveau recherche, publiés ou non, émanant des établissements d'enseignement et de recherche français ou étrangers, des laboratoires publics ou privés. 


\title{
A Sustainable Reconfigurable Manufacturing System Designing With Focus On Environmental Hazardous Wastes
}

\author{
Amirhossein Khezri, Hichem Haddou Benderbal and Lyes Benyoucef \\ Aix Marseille Univ, Universite de Toulon, CNRS, LIS, Marseille, France \\ \{Amirhossein.Khezri, Hichem.haddou-benderbal, Lyes.benyoucef\}@lis-lib.fr
}

\begin{abstract}
Due to awakening environmental awareness and corresponding tightening of environmental protocols in the industrialized world, new production challenges arise. These challenges are to meet the continuously growing worldwide demand for capital and consumer goods while considering the associated economic, environmental, and social aspects. The next generation manufacturing systems must adjust themselves rapidly and cost-effectively. The goal is to respond to changing market needs while minimizing adverse effects on the environment. Reconfigurable Manufacturing Systems (RMSs) - due to its flexibility and characteristics - can increase the system sustainability and responsiveness to satisfy the market needs. In this paper, we propose an environmental oriented multi-objective problem for a sustainable reconfigurable manufacturing system. As design objectives, we consider the total production time, the total production cost and the amount of environmental hazardous wastes. The environmental hazardous wastes considers both liquid hazardous waste and greenhouse gas emissions (GHG). Weighted goal programming is used to tackle this multiobjective problem. The applicability of our approach is illustrated through a numerical example.
\end{abstract}

Keywords-Sustainability; Reconfigurable Manufacturing System; Sustainable Manufacturing; Hazardous Wastes; GHG; Weighted goal programming; Process Planning; Multi-Objective Optimization

\section{INTRODUCTION}

Due to the growing environmental concerns associated with the production and delivery of goods, the "green growth" idea was a crucial point in the October 2016 discussions at United Nations Conference COP21 at Paris. These concerns include amongst other, resource reduction, reducing landfill capacities, human health hazard (liquid hazardous waste and greenhouse gas emissions (GHG)), etc [1]. Manufacturing is an important driver of economic development. It has been recognized that environmental factors are important to the survival of manufacturing companies [2]. Thus, it is very important to consider these factors. More specifically, the emission of Greenhouse gas and liquid hazardous waste during the manufacturing processes. Nevertheless, industries continue to damage the environment, over exploit natural resources and generate uncontrollable amount of wastes.

Environmental criteria's like waste reduction and energy-efficiency are achieved through technological development. The term of Industry 4.0 derived from a high- tech strategy of the German government for automation of manufacturing. It is considered as the $4^{\text {th }}$ industrial revolution. It enables suppliers and manufacturers to leverage new technological concepts like smart manufacturing, which will allow them to overcome the upcoming changes from market. Accordingly, next generation manufacturing systems, must cope with the necessity of rapid product development, flexible manufacturing as well as complicated environments (social, economic and environment). In this context, new or enhanced variety of products and services can be created, cost and delivery time can be reduced and productivity can be increased [3, 4].

Rüßmann et al. [5] introduced advanced manufacturing as a solution to help manufacturing organizations cope with the continuously evolving challenges. It plays a crucial role to upgrade to industry 4.0. It is an integration of set of standardized interfaces, sensors, autonomous and cooperating industrial robots. Due to these characteristics, manufacturers can improve their manufacturing economic and business performance by integrating flexibility and reconfigurability to their design. Furthermore, Reconfigurable Manufacturing Systems (RMSs) have attracted significant attention from researchers and manufacturers due to its ability so called reconfigurability.

RMS is considered as a new class of systems. It takes into consideration numerous aspects like globalization, unstable periodic market changes, mass customization, social changes and rapid technological advances. The term of reconfiguration will allow manufacturer to add, remove, or modify specific process capabilities, controls, software, or machine structure to rapidly adjust production capacity in response to changing market demands. A given RMS configuration can be flexible or dedicated, or a combination of both due the needed changes. Thanks to its flexible structure, customized flexibility and outline focus, RMS considers the effective aspects of both the Dedicated Manufacturing System (DMS) and the Flexible Manufacturing System (FMS) [6].

Due to arising environmental awareness and corresponding tightening of environmental protocols in the industrial world, current developing industries are facing new challenges. Besides, these industries need to meet the continuously growing worldwide demand for capital and consumer goods while considering the associated 
environmental, economic, and social. In this paper, we propose an environmental oriented multi-objective design problem for a sustainable reconfigurable manufacturing system. The objectives consider the total production time, the total production cost as well as environmental hazardous wastes, which count for both liquid hazardous waste and greenhouse gas emissions (GHG). To solve this multiobjective problem, a Weighted goal programming (WGP) approach is used.

The rest of this paper is organized as follows. Section II, presents some related works in the fields of sustainable manufacturing in RMS and process planning problem in RMS environment. Section III, presents our problem description and formulation. Section IV, presents our weighted goal programing based approach to tackle the problem. Section V, shows an illustrative example and discussed results with respect to WGP obtained solutions. Section VI, concludes the paper and outlines future perspectives.

\section{RELATED WORKS}

As an emerging paradigm, RMS is considered as a solution to the recent dynamic environment. It is facing new challenges and many attractions have switched to this system. Designing RMS is complex since it has to provide high quality and high performance [7]. This section presents a brief review of some related works to sustainability in RMS as well as process plan generation in RMS environment is presented.

\section{A. Sustainable manufacturing in RMS}

Choi and Xirouchakis [8] suggested an energy estimation model with focus on a holistic production planning approach in a RMS. Zhang et al. [9] considered a reconfigurable discrete event control system. This system is called reconfigurable and energy-efficient manufacturing systems (REMSs). Their objective was to tackle uncontrolled reconfiguration events and normal events. The authors attempted to model all possible dynamic behavior of the system. This is done by extending a reconfigurable timed net condition/event system (R-TNCES). Afrin et al. [10] proposed a multi-objective optimization problem. They considered simultaneously the cost and carbon footprint of automated production line while satisfying all of its constraints.

As most recent research, Touzout and Benyoucef [11] proposed a multi-objective optimization sustainable process plan generation. The problem considers a single unit product in a reconfigurable environment. In addition to manufacturing criteria's such as cost and time, the authors suggested the amount of the Greenhouse Gas emission (GHG) as an environmental criterion. Moreover, to tackle the problem, they developed an iterative multi-objective integer linear programming (I-MOILP). They also proposed adapted versions of two known metaheuristics; the archived multiObjective simulated annealing (AMOSA) and nondominated sorting genetic algorithm II (NSGA-II). Touzout and Benyoucef [12] extended a sustainable multiunit process plan generation problem in RMS. They solved the problem using three hybrid-metaheuristics including an adapted version of AMOSA with 2-opt heuristic.

\section{B. Process planning in RMS}

Process planning is the initial step in the organization of a manufacturing plant. It shows the sequence of operations that should be perform to manufacture a component. It determines which manufacturing processes, machines, configurations, and tools should be used to perform the operations. Alternatively, "process planning is the systematic determination of methods and means to manufacture a component economically and competitively" [13].

Bensmaine et al. [14] proposed an adapted version of NSGA-II. They solved the problem of machine selection and process plan generating in RMS. Mohapatra et al. [15] proposed a multi-objective model to take into account the integration of process planning and scheduling in RMS. To solve the problem they developed an improved controlled elitist non-dominated sorting genetic algorithm (NSGA). Haddou-Benderbal et al. [16] developed an adapted NSGAII algorithm to find the best alternative process plan when an unavailability of machine occurs. Manupati et al. [17] modeled an integration problem of process planning and scheduling in RMS environment. To solve this problem, the authors proposed two hybrid algorithms, so called modified block-based genetic algorithm (MBBGA) and modified nondominated sorting genetic algorithm (MNSGA-II). Battaïa et al. [18] presented a decision support tool for designing reconfigurable machining systems. The system is used for manufacturing family part products. They expand a costeffective solution for production of several part families.

More recently, Haddou Benderbal et al. [19] addressed the machines selections problem in RMS environment under unavailability constraints. The authors developed an NSGAII based approach. The objective was to ensure the best process plan according to the customized flexibility required to produce all parts of a given product. Haddou Benderbal et al. [20] developed an adapted version of AMOSA to solve the modularity-based optimization problem. For that, they proposed a modularity index alongside cost and production time metrics to guide process plan generation.

\section{PROBLEM DESCRIPTION AND FORMULATION}

\section{A. Problem description}

Due to the numerous input and output streams involved in a product's life, the necessity of considering the coming results and designing a well environmental oriented model, is well recognized. Fig. 1 illustrates the involved streams in a manufacturing process. The hazardous waste comprises amongst other:

- waste oils/water, hydrocarbons/water mixtures, emulsions;

- wastes from the production, formulation and use of resins, latex, plasticizers, glues/adhesives;

- wastes resulting from surface treatment of metals and plastics;

- residues arising from industrial waste disposal operations.

Furthermore, let us consider a single unit of a product to be manufactured. The product requires a set of operations, each of the operations is associated to a set of triplets. Each triplet includes a set of machines, configurations and tools, 


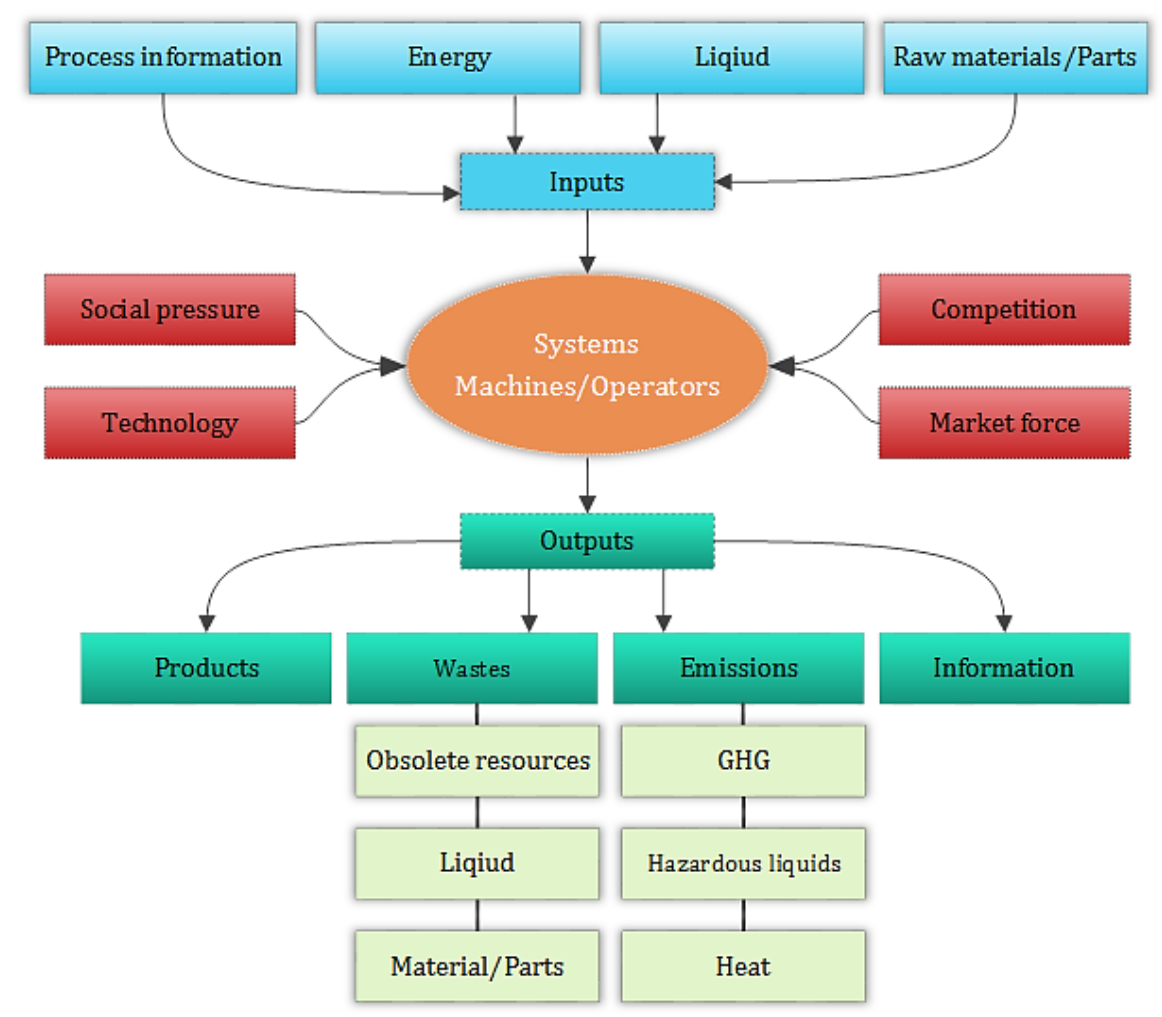

Fig. 1. Involved streams in manufacturing process.

which fulfills the operating process requirements. Moreover, the generated process plan should respect the precedence constraints between the operations.

In this paper, we try to model a sustainable reconfigurable manufacturing system by generating process plan while focusing on environmental hazardous wastes. Thus, the generated process/processes should have the minimum manufacturing and environmental criteria's such as:

1. The amount of wasted hazardous which includes hazardous liquid waste and greenhouse gas emission,

2. The total production cost,

3. The total production time.

\section{B. Problem formulation}

In this section, we propose a multi-objective integer linear programing model. Table I demonstrates the notations, which are used in formulating our problem.

\section{TABLE I}

\section{NOTATIONS AND DECISION VARIABLES}

\begin{tabular}{ll}
\hline Parameters & \\
\hline$O$ & Set of operations \\
$M$ & Set of machines \\
$P_{i}$ & Set of predecessors \\
$T_{i}$ & Set of available triples for $i^{\text {th }}$ operation \\
$T_{m}$ & Set of available triples for $m^{\text {th }}$ machine \\
$n$ & Number of operations \\
$i, i^{\prime}$ & Index of operations
\end{tabular}
$m, m^{\prime}$
Index of machines
$p, p^{\prime} \quad$ Index of positions in the processing
$t, t^{\prime} \quad$ Index of triplets
$t l, t l^{\prime} \quad$ Index of tools
$C, c^{\prime} \quad$ Index of configurations
$C M t_{m, m^{\prime}} \quad$ Changing machine time
$C T t_{t l, t l^{\prime}} \quad$ Changing tool time
$C C t_{c, c^{\prime}} \quad$ Changing configuration time
$P t_{i, t} \quad$ Processing time of $i^{t h}$ operation when using $t^{\text {th }}$ triplet
$C M c_{m, m^{\prime}} \quad$ Changing machine cost
$C T c_{t l, t l^{\prime}} \quad$ Changing tool cost
$C C c_{c, c^{\prime}} \quad$ Changing configuration cost
$P c_{i, t} \quad$ Processing cost of $i^{t h}$ operation when using $t^{\text {th }}$ triplet
$D c_{G H G} \quad$ Residual disposal cost for the emitted GHG
$D c_{H L W}$
Disposal cost for the hazardous liquid waste
$C M e_{m, m^{\prime}} \quad$ Changing machine energy
$C T e_{t l, t l^{\prime}} \quad$ Changing tool energy
$C C e_{c, c^{\prime}} \quad$ Changing configuration energy
$P e_{i, t} \quad$ Processing energy of $i^{t h}$ operation when using $t^{\text {th }}$ triplet
$I E C_{m} \quad$ Initial energy consumption in $m^{\text {th }}$ machine 


$$
\begin{array}{ll}
l_{i, m} & \begin{array}{l}
\text { Required liquid for } i^{t h} \text { operation } m^{t h} \\
\text { machine per time unit }
\end{array} \\
p_{i, m} & \begin{array}{l}
\text { Estimated percentage of hazardous liquid } \\
\text { waste for } i^{t h} \text { operation on } m^{t h} \text { machine }
\end{array} \\
L & \text { Available liquid } \\
f_{g f} & \text { Greenhouse gas emission factor }
\end{array}
$$

\begin{tabular}{|c|c|}
\hline$f_{H L W}$ & $\begin{array}{l}\text { Amount of hazardous liquid waste during } \\
\text { the manufacturing function }\end{array}$ \\
\hline$f_{G H G}$ & $\begin{array}{l}\text { Amount of greenhouse gas emission during } \\
\text { the manufacturing function }\end{array}$ \\
\hline$F_{E H}$ & $\begin{array}{l}\text { Weighted sum of environmental hazard } \\
\text { during the manufacturing process }\end{array}$ \\
\hline$F_{T}$ & Total processing time function \\
\hline$F_{C}$ & Total processing cost function \\
\hline$T_{i}$ & Set of available triples for $i^{t h}$ operation \\
\hline$T_{m}$ & Set of available triples for $m^{t h}$ machine \\
\hline$x_{i, p}^{t}$ & $\begin{array}{l}1 \text { if the } i^{t h} \text { operation is being processed at } \\
\text { the } j^{t h} \text { position using the } t^{t h} \text { triplet, } 0 \\
\text { otherwise. }\end{array}$ \\
\hline$y_{p, t}^{m}$ & $\begin{array}{l}1 \text { if the } m^{t h} \text { machine is using the } t^{t h} \text { triplet } \\
\text { at the } j^{t h} \text { position, } 0 \text { otherwise. }\end{array}$ \\
\hline$m c_{p, m, m^{\prime}}$ & $\begin{array}{l}1 \text { if between position } p-1 \text { and } j \text {, there has } \\
\text { been a change between machines } m \text { and } \\
m^{\prime}, 0 \text { otherwise. }\end{array}$ \\
\hline$t c_{p, t, t^{\prime}}^{m}$ & $\begin{array}{l}1 \text { if between position } p-1 \text { and } j \text {, there has } \\
\text { been a change between triples } t \text { and } \\
t^{\prime}, 0 \text { otherwise. }\end{array}$ \\
\hline
\end{tabular}

Decision variables

$$
\begin{aligned}
& f_{L H W}=\sum_{p=1}^{n} \sum_{m \in M} \sum_{t \in T_{i}} \sum_{i \in O} x_{i, p}^{t} \times l_{i, m} \times P t_{i, t} \times p_{i, m} \\
& f_{G H G}=f_{g f} \times\left(\sum_{p=1}^{n} \sum_{m \in M} \sum_{i \in O} \sum_{t \in T_{i}} y_{p, t}^{m} \times x_{i, p}^{t}\right. \\
& \times \\
&+\sum_{i=1}^{n} \sum_{m} \sum_{i \in T_{i}} x_{i, p}^{t} \\
& \times P e_{i, t} \times P t_{i, t} \\
&+\sum_{p=1}^{n} \sum_{m \in M} \sum_{m^{\prime} \in M} m c_{p, m, m^{\prime}} \\
& \times C M e_{m, m^{\prime}} \times C M t_{m, m^{\prime}} \\
&+\sum_{p=1}^{n} \sum_{m \in M} \sum_{t \in T_{m}} \sum_{t^{\prime} \in T_{m^{\prime}}} t c_{p, t, t^{\prime}}^{m} \\
& \times\left(C T t_{t l, t l^{\prime}} \times C T e_{t l, t l^{\prime}}\right. \\
&\left.\left.+C C t_{c, c^{\prime}} \times C C e_{c, c^{\prime}}\right)\right)
\end{aligned}
$$

$$
\begin{aligned}
F_{E H} & =W_{L H W} \times\left(\frac{f_{L H W}-f_{L H W}^{\min }}{f_{L H W}^{\max }-f_{L H W}^{\min }}\right) \\
& +W_{G H G} \times\left(\frac{f_{G H G}-f_{G H G}^{\min }}{f_{G H G}^{\max }-f_{G H G}^{\min }}\right)
\end{aligned}
$$

Equation (1) presents the amount of hazardous liquid waste for each machine, equation (2) presents the amount of greenhouse gases (GHG) emitted during the manufacturing process. Equation (3) presents our first objective function. It defines the normalized weighted sum of the emitted hazardous liquid and GHG. The assigned weights here, are chosen by the decision-maker.

$$
\begin{aligned}
F_{T}= & \sum_{p=1}^{n} \sum_{i \in O} \sum_{t \in T_{i}} x_{i, p}^{t} \times P t_{i, t} \\
& +\sum_{p=1}^{n} \sum_{m \in M} \sum_{m^{\prime} \in M} m c_{p, m, m^{\prime}} \\
& \times C M t_{m, m^{\prime}} \\
& +\sum_{p=1} \sum_{m \in M} \sum_{k \in K^{m}} \sum_{k^{\prime} \in K^{m^{\prime}}} t c_{p, t, t^{\prime}}^{m} \\
& \times\left(C T t_{t l, t l^{\prime}}+C C t_{c, c^{\prime}}\right) \\
F_{C}=\sum_{p=1}^{n} & \sum_{i \in O} \sum_{t \in T_{i}} x_{i, p}^{t} \times P t_{i, t} \times P c_{i, t} \\
& +\sum_{p=1}^{n} \sum_{m \in M} \sum_{m^{\prime} \in M} m c_{p, m, m^{\prime}} \\
& \times C M c_{m, m^{\prime}} \times C M t_{m, m^{\prime}} \\
& +\sum_{p=1}^{n} \sum_{m \in M} \sum_{t \in T_{m}} \sum_{t^{\prime} \in T_{m^{\prime}}} t c_{p, t, t^{\prime}}^{m} \\
& \times\left(C T t_{t l, t l^{\prime}} \times C T c_{t l, t l^{\prime}}\right. \\
& \left.\left.+C C t_{c, c^{\prime}} \times C C c_{c, c^{\prime}}\right)_{\left(D c_{G H G}\right.} \times f_{G H G}+D c_{H L W} \times f_{H L W}\right)
\end{aligned}
$$

Equation (4) shows our second objective function. It calculates the total production time. Our last objective function is illustrated by equation (5). It calculates the total production cost including disposal cost of the emitted hazardous waste during the production. Note that, as defined in [21], the disposal cost of hazardous waste and emitted GHG include the disposal cost to landfill, recycling, reusing, storing and the residual landfill cost of the emitted GHG.

The following equations represent our problem constraints:

$$
\begin{aligned}
& \sum_{p=1}^{n} \sum_{m \in M} \sum_{t \in T_{i}} x_{i, p}^{t} \times l_{i, m} \times P t_{i, t} \leq L \\
& \sum_{i \in O} \sum_{t \in T_{i}} x_{i, p}^{t}=1 \quad \forall p=1 \ldots n \\
& \sum_{p=1}^{n} \sum_{t \in T_{i}} x_{i, p}^{t}=1 \quad \forall i \in O
\end{aligned}
$$




$$
\begin{array}{cl}
\sum_{t \in T_{i}} x_{i, p}^{t} \times\left|P_{i}\right| & \\
\leq \sum_{t^{\prime} \in T_{i}} \sum_{p^{\prime}=1}^{p-1} \sum_{t^{\prime} \in T_{i^{\prime}}} x_{i^{\prime}, p^{\prime}}^{t^{\prime}} & \\
\sum_{t \in T_{m}} y_{p, t}^{m}=1 & \forall p=1 \ldots n, \forall m \in M \\
y_{p, t}^{m} \geq x_{i, p}^{t} & \forall p=1 \ldots n, \forall m \\
\sum_{i \in O} x_{i, p}^{t}-x_{i, p-1}^{t^{\prime}} & \in M, \forall t \in T_{m} \\
\leq m c_{p, m, m^{\prime}}+1 & \forall p=2 \ldots n, \forall t, t^{\prime} \\
y_{p, t}^{m}+y_{p-1, t^{\prime}}^{m} \leq t c_{p, t, t^{\prime}}^{m} & \forall p=2 \ldots n, \forall m \\
\sum_{t, t^{\prime} \in T_{m}} t c_{p, t, t^{\prime}}^{m}=1 & \forall p=1 \ldots n, \forall m \in M
\end{array}
$$

Constraint (6) represents the limited liquid storage of the manufacturer. Constraints (7) and (8) consider respectively one operation at each position of the process plan, and each operation need to be processed just one time. Constraint (9) considers that each operation should respect the predecessors operations. Constraint (10) represents that each machine can use only one configuration and one tool at once. Constraint (11) considers the requirement of configuration and tool in position $\mathrm{p}$ for $\mathrm{m}^{\text {th }}$ machine. Constraints (12) and (13) consider respectively, if there is a change of machine and a change of configuration and/or tool between position $(p-1)$ and $(p)$. Constraint (14) represents the limitation of only one change of configuration between the $(p-$ 1) and $(p)$.

In order to transform our non-linear model to a linear model, we use the constraints represented by equation (15). The goal of this transformation is to eliminate the multiplication operator

$$
\begin{aligned}
& y_{p, t}^{m} \times x_{i, p}^{t} \equiv z \\
& \text { S.t. } \\
& z \leq x_{i, p}^{t} \\
& z \leq y_{p, t}^{m} \\
& z \geq y_{p, t}^{m}+x_{i, p}^{t}-1 \\
& z \in\{0,1\}
\end{aligned}
$$

\section{MULTI-OBJECTIVE PROPOSED APPEROACH}

In this section, we describe more in details the proposed weighted goal programming (WGP). This approach is used to tackle our multi-objective optimization problem.

The overall purpose of goal programming (GP) is to minimize the deviations between the achievement of the goals and their aspirational levels. WGP considers all goals simultaneously as they are embodied in a composite objective function.

The algebraic structure of a WGP model is:

$$
\begin{gathered}
\operatorname{Min} \sum_{i=1}^{p}\left(w_{i}^{+} \times d_{i}^{+}+w_{i}^{-} \times d_{i}^{-}\right) \\
\text {S.t. } \\
F n_{i}(x)+d_{i}^{-}-d_{i}^{+}=F n_{i}^{*}\left(x_{i}^{*}\right), \quad i=1, \ldots, p \\
x \in F n \\
x \geq 0 \quad d^{-} \geq 0 \quad d^{+} \geq 0
\end{gathered}
$$

Where $d^{+}, d^{-}$are the deviations, $F n^{*}\left(x^{*}\right)$ is the goal of objective function, and $w^{+}, w^{-}$indicates the assigned weight to each deviation.

The following pseudo code describes the weighted goal based approach. Firstly, we try to solve each objective separately to obtain the goals. Secondly, generating N sets of weights. These weights are used in each iteration to minimize the aggregate of the objective function derivations. Finally, the resulted solutions will form the Pareto frontier.

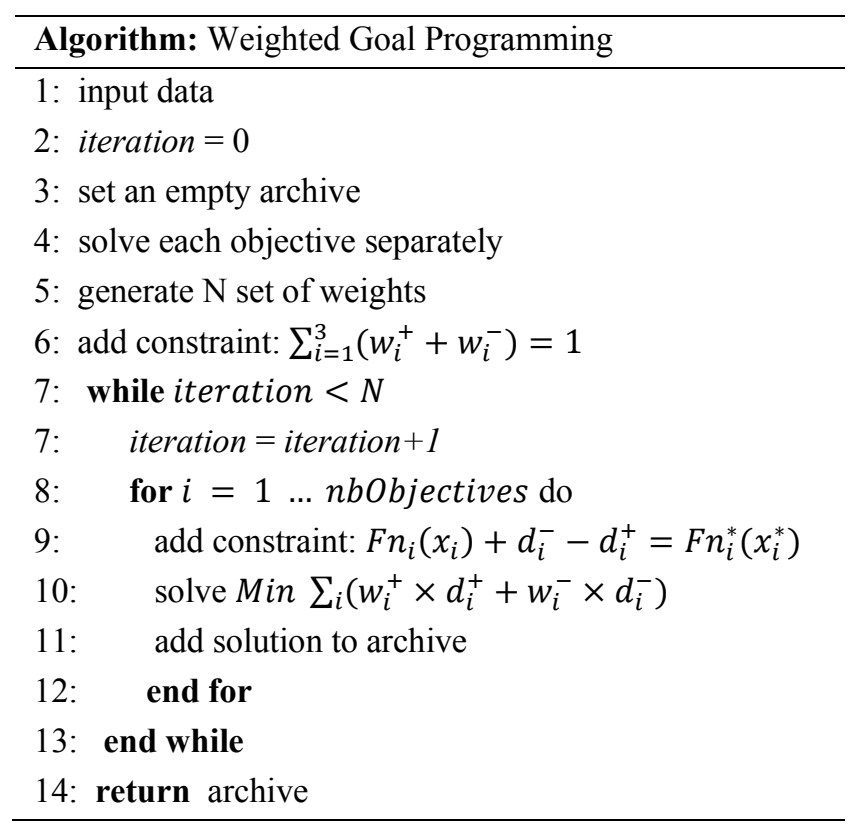

\section{NUMERICAL EXPERIMENT}

In this section, we present the applicability of our approach through an illustrative numerical example. The example is implemented in GAMS 24.9 on a pc with the following configuration: (i) Core i7 and 2.20Ghz processor (ii) 8 GB RAM.

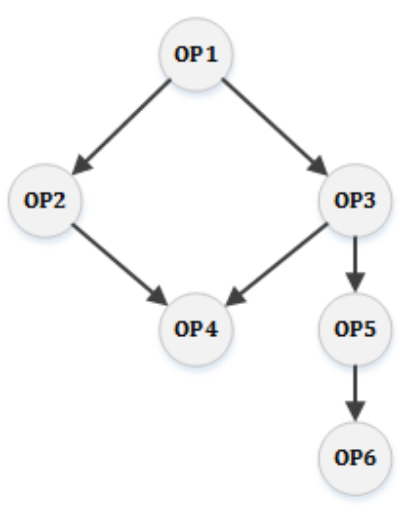

Fig. 2. The precedence graph 
We need to produce a single product that requires six operations. These operations can be realized on two reconfigurable machines $\mathrm{M} 1$ and $\mathrm{M} 2$, with three different configurations and three different tools. The set of required operations must respect the precedence graph as shown in Fig. 2.

Table II shows the possible requirements of machine, configuration and tool for each operation. As an example, operation 5 (fifth line) can be operated on M2 using configuration $\mathrm{C} 3$ and tool $\mathrm{T} 1$ or also, can be done on M2, with configuration $\mathrm{C} 2$ and tool $\mathrm{T} 1$.

TABLE II OPERATIONS REQUIREMENTS

\begin{tabular}{|c|c|c|c|}
\hline Operation & Machine & Configuration & Tool \\
\hline \multirow{2}{*}{$O P_{1}$} & $M_{1}$ & $C_{1}$ & $T_{2}$ \\
& $M_{2}$ & $C_{1}$ & $T_{3}$ \\
\hline \multirow{2}{*}{$O P_{2}$} & $M_{1}$ & $C_{2}$ & $T_{3}$ \\
& $M_{2}$ & $C_{1}$ & $T_{1}$ \\
\hline \multirow{2}{*}{$O P_{3}$} & $M_{2}$ & $C_{3}$ & $T_{1}$ \\
\hline$O P_{4}$ & $M_{2}$ & $C_{1}$ & $T_{2}$ \\
\hline \multirow{2}{*}{$O P_{5}$} & $M_{2}$ & $C_{3}$ & $T_{2}$ \\
\hline \multirow{2}{*}{$O P_{6}$} & $M_{2}$ & $C_{3}$ & $T_{1}$ \\
& $M_{2}$ & $C_{2}$ & $T_{1}$ \\
\hline & $M_{1}$ & $C_{3}$ & $T_{2}$ \\
\hline
\end{tabular}

With respect to equation (3), we have assigned equal weights to our sustainability objectives as shown in equation (17).

$$
\begin{aligned}
F_{E H}= & 0.5 \times\left(\frac{f_{L H W}-f_{L H W}^{m i n}}{f_{L H W}^{m a x}-f_{L H W}^{\min }}\right)+ \\
& 0.5 \times\left(\frac{f_{G H G}-f_{G H G}^{\min }}{f_{G H G}^{\max }-f_{G H G}^{\min }}\right)
\end{aligned}
$$

TABLE III

PAYOFF TABLE OF THE OBJECTIVES

\begin{tabular}{|c|c|c|}
\hline $\boldsymbol{F}_{\boldsymbol{T}}$ & $\boldsymbol{F}_{\boldsymbol{C}}$ & $\boldsymbol{F}_{\boldsymbol{E H}}$ \\
\hline 930 & 41730 & 0.1489 \\
\hline 1417 & 26002 & 0.0479 \\
\hline 1945 & 49050 & 0.0013 \\
\hline
\end{tabular}

Table III represents the payoff table of each objectives where each objective is optimized separately with respect to the constraints. As shown in Table III the best total production in absence of the other objectives is 930 (minute), respectively, the total production cost is $26002(€)$ and the best amount of hazardous waste is 0.0013 hazardous unit (H.u).

TABLE IV

MIN AND MAX OF THE SUSTAINABLE OBJECTIVES FOR NORMALIZING

\begin{tabular}{|c|c|c|}
\cline { 2 - 3 } \multicolumn{1}{c|}{} & $\boldsymbol{F}_{\boldsymbol{H} \boldsymbol{W}}$ & $\boldsymbol{F}_{\boldsymbol{G H G}}$ \\
\hline $\boldsymbol{M i n}$ & 20.150 & 15150 \\
\hline $\boldsymbol{M a x}$ & 120.400 & 19295700 \\
\hline
\end{tabular}

Table IV shows the minimum and maximum of the amount of hazardous liquid waste and amount of emitted GHG.

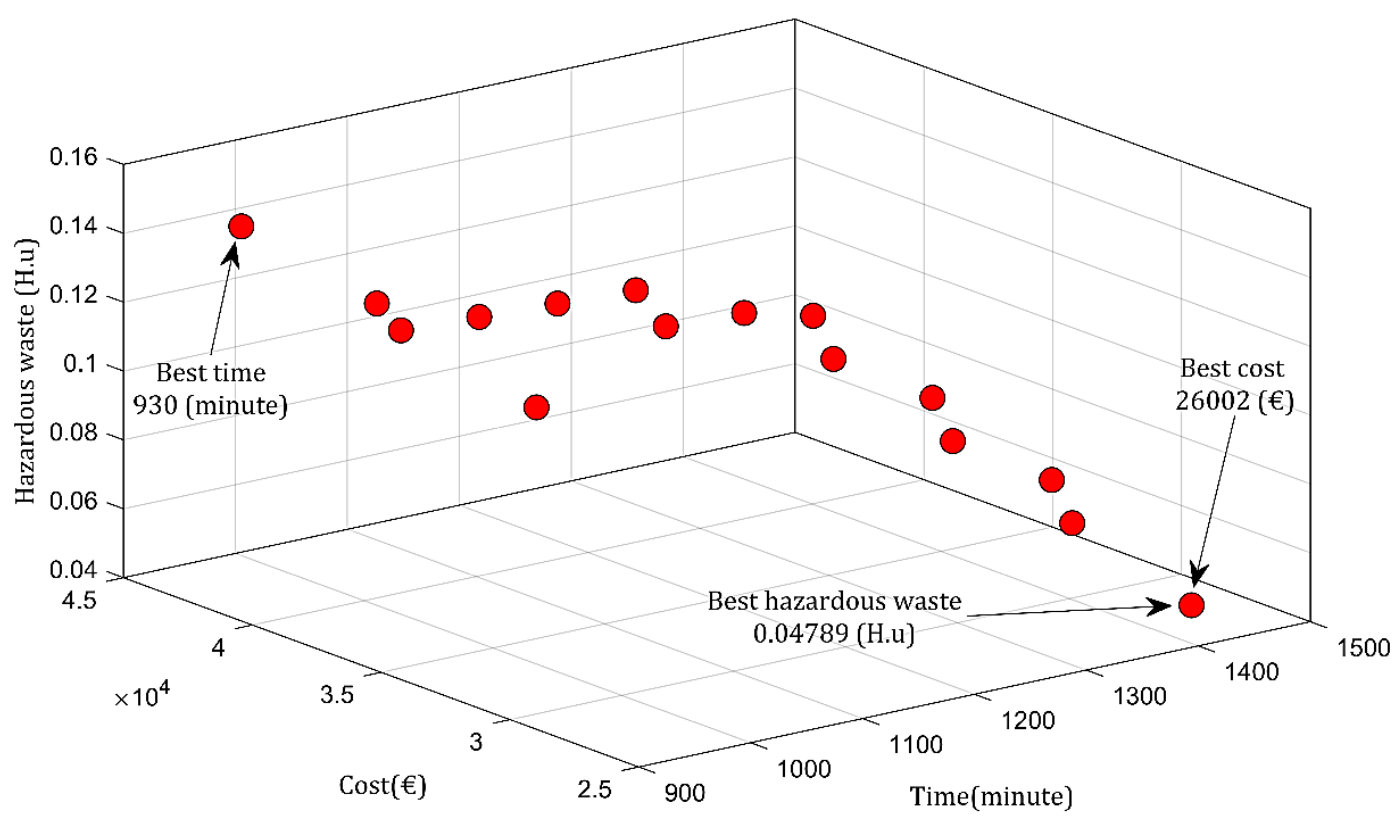

Fig. 3. Obtained Pareto frontier solutions using WGP 
Fig. 3 represents the obtained Pareto frontier solutions while using WGP to tackle the problem. This frontier is obtained with 16 solutions in set of Pareto solutions. With respect to the solutions, best resulted total production time gains in 930 (minute) where the total cost production is $41730(€)$ and the amount of hazardous waste is 0.1489 (H.u). The best obtained total production cost is $26002(€)$ where the total production time is 1417 (minute) and the amount of hazardous waste is 0.0479 (H.u). Furthermore, the best obtained amount of hazardous waste among our Pareto solutions is 0.0479 (H.u) where the total production time is 1417 (minute) and the total production cost is $26002(€)$.

Fig. 4 illustrates the best resulted total production cost and emitted hazardous waste among our Pareto solution sets. As shown in Fig. 4, this process plan considers only one change in machines; therefore, the final product can be manufactured in less cost by the change in the machines.

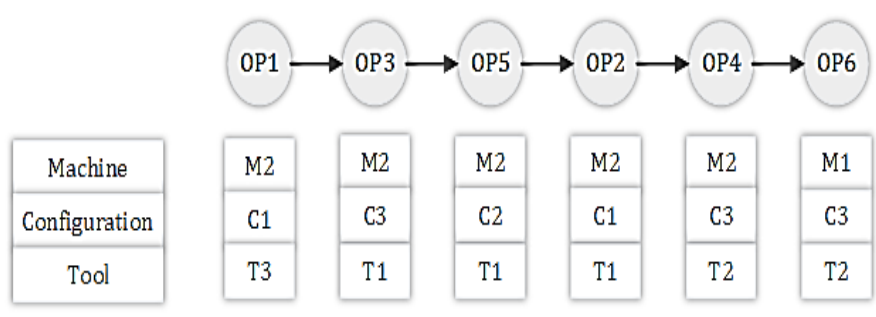

Fig. 4. Assigned set of triplet to the illustrated solution example

\section{CONCLUSION}

In this work, we studied sustainability from liquid and greenhouse gases point of view. In this context, we have proposed a hazardous waste mathematical model for a sustainable reconfigurable manufacturing environment. Moreover, we considered two classical objectives namely the total production cost and total production time. To find the Pareto frontier, an adapted version of weighted goal programming is used to solve the problem.

To demonstrate the applicability of our model, an illustrative example was given and experimental results were discussed. Interesting topics for future research directions can include developing heuristic approaches or an integration model of process planning and scheduling in a sustainable reconfigurable manufacturing environment.

\section{REFERENCES}

[1] R. N. Stavins and R. C. Stowe, "The Paris agreement and beyond: International climate change policy post-2020," Harvard Project on Climate Agreements, 2016.

[2] D. Beekaroo, D. S. Callychurn, and D. K. Hurreeram, "Developing a sustainability index for Mauritian manufacturing companies," Ecological Indicators, vol. 96, pp. 250-257, 2019.

[3] V. Vyatkin, Z. Salcic, P. S. Roop, and J. Fitzgerald, "Now that's smart!," IEEE Industrial Electronics Magazine, vol. 1, no. 4, pp. 17-29, 2007.

[4] S. Heng, "Industry 4.0: upgrading of Germany's industrial capabilities on the horizon," Available at SSRN 2656608, 2014.

[5] M. Rüßmann et al., "Industry 4.0: The future of productivity and growth in manufacturing industries," Boston Consulting Group, vol. 9, no. 1, pp. 54-89, 2015.

[6] Y. Koren and M. Shpitalni, "Design of reconfigurable manufacturing systems," Journal of manufacturing systems, vol. 29, no. 4, pp. 130-141, 2010.

[7] Y. Zhao, "Optimal operation of panel furniture reconfigurable manufacturing system based on TCPN and GA," in Proceedings of 2011
International Conference on Electronic \& Mechanical Engineering and Information Technology, 2011, vol. 4, pp. 2179-2182: IEEE.

[8] Y.-C. Choi and P. Xirouchakis, "A holistic production planning approach in a reconfigurable manufacturing system with energy consumption and environmental effects," International Journal of Computer Integrated Manufacturing, vol. 28, no. 4, pp. 379-394, 2015.

[9] J. Zhang et al., "Modeling and verification of reconfigurable and energy-efficient manufacturing systems," Discrete Dynamics in Nature and Society, vol. 2015, 2015.

[10] K. Afrin, A. S. Iquebal, S. K. Kumar, M. Tiwari, L. Benyoucef, and A. Dolgui, "Towards green automated production line with rotary transfer and turrets: a multi-objective approach using a binary scatter tabu search procedure," International Journal of Computer Integrated Manufacturing, vol. 29 , no. 7 , pp. 768-785, 2016.

[11] F. A. Touzout and L. Benyoucef, "Multi-objective sustainable process plan generation in a reconfigurable manufacturing environment: exact and adapted evolutionary approaches," International Journal of Production Research, pp. 1-17, 2018.

[12] F. A. Touzout and L. Benyoucef, "Sustainable multi-unit process plan generation in a reconfigurable manufacturing environment: A comparative study of three hybrid-meta-heuristics," in 2018 IEEE 23rd International Conference on Emerging Technologies and Factory Automation (ETFA), 2018, vol. 1, pp. 661-668: IEEE.

[13] N. Jain and V. Jain, "Computer aided process planning for agile manufacturing environment," Agile Manufacturing: The 21st Century Competitive Strategy, Elsevier, Oxford, pp. 515-534, 2001.

[14] A. Bensmaine, M. Dahane, and L. Benyoucef, "A non-dominated sorting genetic algorithm based approach for optimal machines selection in reconfigurable manufacturing environment," Computers \& Industrial Engineering, vol. 66, no. 3, pp. 519-524, 2013.

[15] P. Mohapatra, A. Nayak, S. Kumar, and M. Tiwari, "Multi-objective process planning and scheduling using controlled elitist non-dominated sorting genetic algorithm," International journal of production research, vol. 53, no. 6 , pp. 1712-1735, 2015.

[16] H. Haddou-Benderbal, M. Dahane, and L. Benyoucef, "Hybrid heuristic to minimize machine's unavailability impact on reconfigurable manufacturing system using reconfigurable process plan," IFACPapersOnLine, vol. 49, no. 12, pp. 1626-1631, 2016.

[17] V. K. Manupati, P. Chang, and M. K. Tiwari, "Intelligent search techniques for network-based manufacturing systems: multi-objective formulation and solutions," International Journal of Computer Integrated Manufacturing, vol. 29, no. 8, pp. 850-869, 2016.

[18] O. Battaïa, A. Dolgui, and N. Guschinsky, "Decision support for design of reconfigurable rotary machining systems for family part production," International Journal of Production Research, vol. 55, no. 5, pp. 1368-1385, 2017.

[19] H. Haddou Benderbal, M. Dahane, and L. Benyoucef, "Flexibilitybased multi-objective approach for machines selection in reconfigurable manufacturing system (RMS) design under unavailability constraints," International Journal of Production Research, vol. 55, no. 20, pp. 60336051,2017

[20] H. Haddou Benderbal, M. Dahane, and L. Benyoucef, "Modularity assessment in reconfigurable manufacturing system (RMS) design: an Archived Multi-Objective Simulated Annealing-based approach," The International Journal of Advanced Manufacturing Technology, vol. 94, no. 1-4, pp. 729-749, 2018.

[21] Hazardous Waste (Regulation of Exports and Imports) Act II 1989 for Australia.

https://www.legislation.gov.au/Details/C2017C00194.
Available: 